\section{Attack during differential reinforcement of a low rate of responding}

JOHN F. KNUTSON, University of Iowa, Iowa City, Iowa 52240, and RONALD A. KLEINKNECHT, University of Oregon Medical School, Eugene, Oreg. 97403

Pigeons submitted to sessions of continuous reinforcement (CRF) and sessions of differential reinforcement of a low rate of responding (DRL $20 \mathrm{sec}$ ) attacked a restrained target pigeon during DRL 20 but not during CRF. Comparing these results to previously reported data, it was suggested that reinforcement density, as well as the nonreinforced responses, contributed to the aggression elicited by intermittent schedules of reinforcement.

A variety of parameters frequently employed in behavioral manipulations have been shown to elicit aggression between paired organisms. The presentation of aversive stimuli, such as electric shock (Ulrich \& Azrin, 1962), a physical blow (Azrin, Hake, \& Hutchinson, 1965), or morphine withdrawal (Boshka, Weisman, \& Thor, 1966), resulted in one organism attacking another organism or an inanimate target apparatus. Most recently, pigeons and primates submitted to fixed-ratio (FR) reinforcement for an operant response attacked when given access to a target (Gentry, 1968; Hutchinson, Azrin, \& Hunt, 1968). Knutson (1970), using pigeons in a standard key-peck paradigm, demonstrated that continuous reinforcement and FR schedules with low response requirements (FR 15 and FR 25) did not result in aggression directed at a target pigeon, whereas FR schedules with larger response requirements (FR 40, FR 60, and FR 120) regularly resulted in attack behavior. In considering the aggression-eliciting aspects of intermittent reinforcement, it is reasonable to ask whether the attack behavior during FR reinforcement is a function of the increased response requirement or the decreased frequency of reinforcement.

In an attempt to clarify this question, the present investigation sought to determine if an intermittent schedule of reinforcement characterized by infrequent reinforcement and a low response requirement would result in elicited aggression in a pigeon paired with a restrained target pigeon. Differential reinforcement of a low rate of responding (DRL) was considered the schedule of choice because it would maintain low response rates and infrequent reinforcement.
METHOD
The four Ss were experimentally naive male adult White Carneaux pigeons maintained at $80 \%$ of their free-feeding weights. Each experimental bird was paired with a target pigeon maintained at ad lib body weight. The experimental chamber was similar to that described by Azrin, Hutchinson, \& Hake (1966). At one end of the chamber was a standard aluminum operant-conditioning pigeon chamber interior, including a houselight, a transilluminated response key $2.5 \mathrm{~cm}$ in diam, and a feeding aperture with a grain hopper which could be raised into position for $5 \mathrm{sec}$ to provide food reinforcement. At the opposite end of the chamber, $35 \mathrm{~cm}$ from the response key, was a restraining device consisting of a Plexiglas box mounted on a stablimeter. The target pigeon was held in a stationary position in the box and was able to move only its head and neck. Plexiglas shields to the sides of the target insured that all attack would be directed at the front of the apparatus. An inverted U-shaped Plexiglas frame on the front of the restraining box minimized injury to the target when attacked by the experimental animal. Aggressive responding was recorded whenever the restraining stablimeter was displaced by a blow in excess of $125 \mathrm{~g}$. The experimental contingencies were controlled by means of conventional relay circuitry; key-peck responding and attack were recorded on cumulative recorders.

Following adaptation to the experimental chamber, the naive experimental pigeons were placed in the chamber with the restrained target bird for daily $45-\mathrm{min}$ sessions. Following five such sessions, the target birds were removed and the experimental pigeons were trained to eat from the food hopper and then shaped to key peck. Following three sessions consisting of 60 continuously reinforced responses, the target birds were returned to the apparatus and each experimental pigeon was given five daily sessions of 60 key pecks on a continuous reinforcement (CRF) schedule with the target bird

\section{Table 1}

The Response Rates and Reinforcement Rates During DRL 20. The data are combined over the last 6 days immediately preceding the reintroduction of the target pigeon.

\begin{tabular}{lcccc}
\hline & \multicolumn{3}{c}{ Subjects } \\
\cline { 2 - 5 } & 1 & 2 & 3 & 4 \\
\hline Responses/Minute & 6.9 & 7.2 & 9.6 & 9.1 \\
Reinforcements/Minute & 0.24 & 0.40 & 0.28 & 0.41 \\
Responses/Reinforcement & 28.7 & 18.0 & 34.2 & 22.2 \\
\hline
\end{tabular}
frequency of short interresponse times (IRT) and improve the DRL performance, IRTs less than $20 \mathrm{sec}$ resulted in a 10-sec timeout (TO) consisting of an extinguishing of both the houselight and the response key (Kramer \& Rilling, 1969). This procedure was followed for 8 to 10 sessions, then the TO contingency for IRTs less than $20 \mathrm{sec}$ was removed. The experimental pigeons were continued on DRL 20 for 8 to 16 sessions without a target bird present. A slight increase in response rate and a decrease in the frequency of reinforcement followed the removal of the TO contingency, but this DRL 20 performance was superior to that prior to the introduction of the TO contingency. Table 1 shows the response rate and reinforcement density for each bird for the combined final six sessions prior to the reintroduction of the target.

When the DRL 20 performance was stable, the target pigeons were reintroduced to the apparatus and the experimental birds were run on a DRL 20 for $45 \mathrm{~min}$ for five sessions. In order to avoid the development of a superstitious concurrence of attack and key pecking, or the development of attack as a mediating response during the DRL, a change-over delay (COD) was included. Each attack response started a timer that established a period of time during which no key-peck response would be reinforced. Because there are no guidelines for CODs in concurrent operants using DRLs (Catania, 1966), a rather conservative procedure involving a COD equal to the IRT requirement of the DRL $20 \mathrm{sec}$ was used.

Following their five sessions at DRL 20, the target pigeons were again removed and each experimental pigeon was run on CRF for four sessions to reestablish stable CRF key-peck performance. The targets were then returned to the apparatus and each experimental bird was nun for five sessions on a CRF schedule until 60 reinforcements had been delivered.

\section{RESULTS AND DISCUSSION}

No aggression was displayed when the naive experimental pigeons were placed present. Following these five sessions, the targets were removed and the experimental Ss were submitted to a DRL schedule. Over a period of 25 to 31 sessions, the DRL requirement was gradually increased from 2 to $20 \mathrm{sec}$. In order to reduce the

Psychon. Sci., 1970, Vol. 19 (5) 

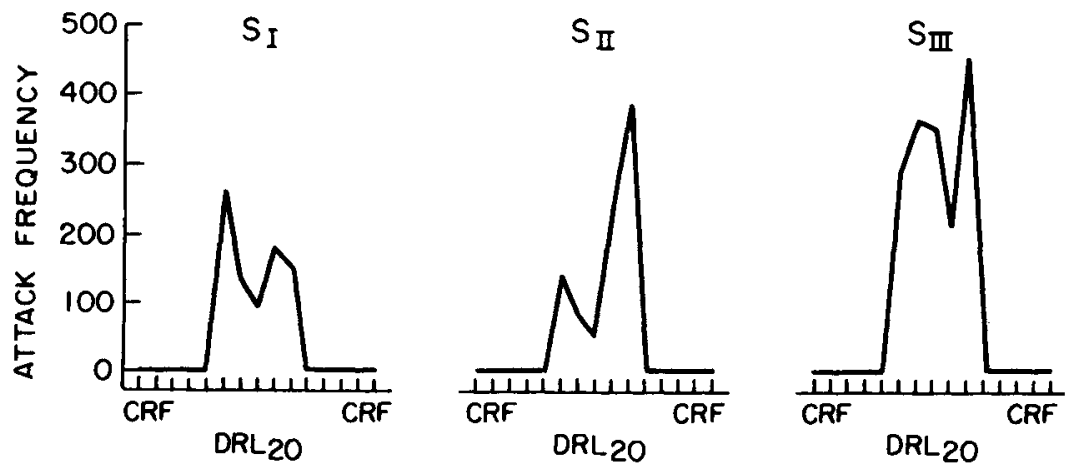

with the targets prior to magazine training and shaping. Similarly no attack behavior occurred during the first five sessions incorporating CRF. The introduction of the target birds during DRL 20 resulted in attack behavior in all four Ss. Figure 1 shows the frequency of attack during each 45-min session during CRF and DRL 20 for three of the four Ss. It can be seen that the DRL 20 was associated with attack behavior, but CRF reinforcement was not associated with attack responding in these three Ss. The variability in the frequency of attack for these three $S s$ is quite apparent. The fourth $S$ displayed a frequency of attack far greater than the other three birds; the rate of responding (22-30 blows per minute) was so great that three of five sessions were terminated early to avoid serious injury to the target bird. Even in these abbreviated sessions, this $S$ evidenced an attack frequency that was far higher than that of the other Ss. The frequency of attack and the variability between and within Ss is consistent with earlier results showing attack during intermittent reinforcement (Gentry, 1968). The lack of aggression during CRF was consistent with Azrin et al (1966) and Knutson (1970). The fourth $S$ evidenced some attack behavior during the initial minutes of the first two sessions of the second block of CRF sessions. This behavior terminated rapidly and was not displayed during later sessions.

Gentry (1968) had demonstrated that most attack during FR 50 was coincidental with the postreinforcement pauses. Knutson (1970) noted that during FR 40 and FR 60 the attack behavior typically coincided with postreinforcement pauses. In the present study, attack during DRL 20 was found to be distributed throughout the entire session. While the DRL 20 has a much lower number of nonreinforced responses than FR 120, both schedules are associated with a low density of reinforcement. Perhaps it is the reinforcement density which determines whether attack will occur during a period of time closely following reinforcement.

The results of this study indicate that in Ss with a history of CRF, intermittent schedules of reinforcement other than FR will result in attack between paired organisms. Because the DRL performance of the pigeon is quite inefficient and there are numerous nonreinforced responses (shown in Table 1), it is impossible to determine from these data whether attack during intermittent reinforcement is solely a function of the low frequency of
Fig. 1. The frequency of aggressive responses made against a target pigeon by Pigeons 1, 2, and 3 during sessions of continuous reinforcement and DRL 20 reinforcement.

reinforcement. Because the number of nonreinforced responses during DRL 20 was considerably lower than during the FR 120 of the earlier study, while the attack frequency was comparable, it is likely that density of reinforcement is an important factor in the attack behavior elicited by intermittent reinforcement.

\section{REFERENCES}

AZRIN, N. H., HAKE, D. F., \& HUTCHINSON, R. R. Elicitation of aggression by a physical blow. Journal of the Experimental Analysis of Behavior, 1965, 8, 55-57.

AZRIN, N. H., HUTCHINSON, R. R., \& HAKE, D. F. Extinction induced aggression. Journal of the Experimental Analysis of Behavior, 1966, 9, 191-204.

BOSHKA, S. C., WEISMAN, H. M., \& THOR, D. H. A technique for inducing aggression in rats utilizing morphine withdrawal. Psychological Record, 1966, 16, 541-543.

CATANIA, A. C. Concurrent operants. In W. K. Honig (Ed.), Operant behavior: Areas of research and application. New York: Appleton-Century-Crofts, 1966. Pp. 213-270.

GENTRY, W. D. Fixed-ratio schedule-induced aggression. Journal of the Experimental Analysis of Behavior, 1968, 11, 813-817.

HUTCHINSON, R. R., AZRIN, N. H., \& HUNT, G. M. Attack produced by intermittent reinforcement of a concurrent operant response. Journal of the Experimental Analysis of Behavior, 1968, 11, 489-495.

KNUTSON, J. F. Aggression during the fixed-ratio and extinction components of a multiple schedule of reinforcement. Journal of the Experimental Analysis of Behavior, 1970, 13, 221.231.

KRAMER, T. J., \& RILLING, M. Effects of timeout on spaced responding in pigeons. Journal of the Experimental Analysis of Behavior, 1969, 12, 283-288.

ULRICH, R. E., \& AZRIN, N. H. Reflexive fighting in response to aversive stimulation. Joumal of the Experimental Analysis of Behavior, 1962, 5, 511-520. 